\title{
Auxílio-funeral na assistência social: atenção para quem?
}

\author{
Funeral aid in social welfare: Caring for whom?
}

\section{Gisele Aparecida BOVOLENTA*}

\begin{abstract}
Resumo: $\mathrm{O}$ cuidado com o corpo morto é uma das atenções mais antigas que existe. No âmbito da política de assistência social está afiançado desde 1993 o auxílio-funeral como uma das modalidades de benefício eventual da Lei Orgânica de Assistência Social (LOAS) no campo dos direitos sócioassistenciais. Esta reflexão propõe identificar o trato dispensado ao funeral ao longo da história e sua aproximação com a política de assistência social. A partir de uma análise bibliográfica, documental, legal e empírica, tendo a cidade de São Paulo como lócus dessa reflexão, busca-se compreender o papel desse auxílio no âmbito da política de assistência social e o modo como ele se encontra no país.
\end{abstract}

Palavras-Chave: Auxílio-funeral. Política de Assistência Social. Benefício eventual. Proteção social. Família.

\begin{abstract}
Caring for the deceased body is one of the oldest forms of care there is. In the context of social welfare policy, funeral assistance has been available since 1993 as one of the forms of final benefits of the Organic Law on Social Welfare (LOAS) in the field of social welfare rights. This reflective article proposes to identify the treatment given to funerals throughout history and its proximity to social welfare policy. Based on a bibliographical, documentary, legal and empirical analysis, with the city of São Paulo as the locus, this article seeks to understand the role of this aid within the scope of social welfare policy and how it takes place across the country.

Keywords: Funeral assistance. Social Welfare. Final benefit. Social protection. Family.
\end{abstract}

\section{Introdução}

Submetido em: 18/7/2017. Aceito em: 5/12/2017.

Este texto traz como objeto de reflexão o auxílio-funeral previsto na política de assistência social, reconhecido na LOAS como uma das modalidades de benefício eventual, conforme Art. 22. A partir de uma revisão bibliográfica, análise documental-legal, pesquisa empírica com dados de realidade, os apontamentos aqui apresentados buscam identificar o trato dispensado ao funeral ao longo do tempo e sua aproximação com a política de assistência social, tomando por base a realidade da cidade de São Paulo. Interessa-nos identificar as formas de atenção historicamente existentes perante a vivência do óbito, bem como o apoio dispensado (ou não) pelo Estado em tal momento. Do mesmo modo, considera-se relevante compreender qual é de fato o papel do auxílio-funeral no âmbito da política de assistência social e a quem se destina.

Inicialmente é necessário nesta análise demarcar a diferença entre o sepultamento, compreendido como o enterro do corpo morto - a partir de todo seu rito, burocracia e história -, e o auxílio-funeral no âmbito da política de assistência social, apreendido como

\footnotetext{
${ }^{1}$ Algumas reflexões apresentadas neste artigo foram trabalhadas em minha Tese de Doutorado em Serviço Social, defendida junto à PUCSP em abril de 2016, a qual contou com apoio da CAPES.

${ }^{*}$ Assistente Social. Mestre e Doutora em Serviço Social pela PUCSP. Docente em Serviço Social na Fundação Municipal de Ensino Superior de Bragança Paulista (SP) (FESB, Bragança Paulista, Brasil). E-mail: <gibovolenta@yahoo.com.br>.
}

Argum., Vitória, v. 9, n. 3, p. 98-112, set./dez. 2017. 
um suporte, proteção e apoio aos familiares e/ou dependentes do morto, sobretudo se este desempenhava o papel de arrimo da família. Compreender essas diferenças contribui na defesa de que o auxílio-funeral assegurado junto à política de assistência social não deve se comportar como o pagador de taxas do cemitério ou o facilitador da burocracia acerca do sepultamento, mas sim, como parte do campo de proteção social que garanta apoio e suporte à família perante o óbito, por vezes inesperado e atípico em seu cotidiano.

\section{O funeral ao longo da história e sua aproximação com a assistência social}

Ao percorrer a história é possível identificar que o cuidado com o morto e a vivência do luto constituem-se em episódios desde os mais longínquos tempos da humanidade, permeados por ritos, tradições e costumes específicos de cada época, sociedade e cultura, que não se limitavam (e limitam) ao enterro do corpo morto em si.

Com a chegada dos portugueses ao Brasil e a imposição do catolicismo como religião oficial, a busca pela salvação da alma passou a compor os ritos fúnebres da "boa morte". Era comum, até o século XIX, os mortos serem enterrados no interior de igrejas ou em outros lugares considerados sagrados, pois se acreditava que isso permitiria a tão almejada salvação da alma no dia do Juízo Final. A Igreja Católica preocupava-se com a alma, embora boa parte da sociedade atribuísse um valor social ao corpo, pois este, mesmo sem vida, era carregado de símbolos que o diferenciava dos outros. “[...] Nem mesmo diante da morte os corpos são iguais, já que ainda carregam consigo as marcas das diferentes situações que tiveram em vida" (CAMARGO, 2007, p. 398). Ou seja, as diferenças sociais (por classe, raça, idade e condição socioeconômica) não cessavam com o advento da morte; ao contrário, permaneciam imprimindo as contradições sociais existentes na sociedade e vivenciadas pelas pessoas ao longo da vida. Nesse sentido, a "boa morte" era a extensão dessas diferenças em vida: as famílias mais afortunadas cuidavam, com os devidos méritos e pompas, de seus falecidos, assegurando que o rito fúnebre preservasse sua memória, lhe desse todo conforto durante o "descanso eterno" e lhe garantisse o Reino dos Céus. Não à toa, os ricos eram enterrados em lugares privilegiados no interior das igrejas, como os mais próximos do altar ou dos santos intercessores, por acreditar que assim estariam seguros e protegidos no dia do Juízo Final.

O momento da morte era, muitas vezes, organizado e preparado antecipadamente. Era comum as pessoas mais abastadas escreverem testamentos em que indicavam como deveria ser o funeral, o cortejo e a cerimônia de enterro. Neste contexto, inclusive, a morte se constituía num verdadeiro "[...] encontro social [...]" entendido "[...] como uma oportunidade para a afirmação de fortuna e poder” (PAGOTO, 2002, p. 73).

A velhice "[...] era caracterizada pela preparação para a morte por meio do Rosário à noite, testamento e missa diária”2 (REIS, 1997, p. 101). Também era comum, nessa reta final da vida, reparar velhos pecados da carne: era o momento em que "[...] pais reconheciam filhos tidos

\footnotetext{
${ }^{2}$ Fragmento extraído de um artigo de 1836, no Diário da Bahia, que definia os vários estágios do ciclo da vida: a velhice se localizava entre 64 e 70 anos, momento em que as pessoas deveriam preparar e organizar sua morte (REIS, 1997).
}

Argum., Vitória, v. 9, n. 3, p. 98-112, set./dez. 2017. 
de relações ilícitas e homens casavam com amásias, às vezes ex-escravas, fazendo-as herdeiras legítimas" (REIS, 1997, p. 106).

Aos pobres 3 , a vivência da morte configurava-se sempre como um verdadeiro transtorno e sofrimento. Por serem desprovidos de bens, a solução, no caso, era apelar para a caridade alheia a fim de garantir que seus entes queridos fossem enterrados condignamente e em solo sagrado, "[...] mesmo que isso implicasse em conseguir uma sepultura em lugar menos privilegiado, como o adro ou o cemitério intra-muros" (PAGOTO, 2002, p. 75).

Preocupados com a salvação da alma,

[...] quando a família não conseguia auxílio para sepultar os seus mortos em solo sagrado, a solução encontrada era abandoná-los à porta de uma igreja ou sepultá-los, clandestinamente nos cemitérios paroquiais (intra-muros) de madrugada (PAGOTO, 2002, p. 75).

Por sua vez, os escravos, indigentes, presos, pessoas condenadas à morte, vítimas de doenças contagiosas ou que professassem outra religião eram enterradas em lugares ainda mais distantes das cidades. A eles não se dava o direito de serem sepultados em solo sagrado por não serem socialmente aceitos nesses espaços, uma vez que não eram considerados cristãos.

Durante a Colônia, o Império e também durante a República é possível identificar diversas formas de auxílio e apoio dispensados às pessoas perante a perda de um ente querido, o que em geral se dava por meio de ações caritativas ou por incipientes instrumentos legais.

Sepultar os mortos era uma das Quatorze Obras de Misericórdia ${ }^{4}$ conduzidas pelas Santas Casas. Era através delas que parte dos indigentes, pobres e excluídos recebia guarida, por meio da compaixão de seus mantenedores em relação ao sofrimento alheio no momento do “descanso eterno”. A Igreja também procurava ser piedosa diante do fim da vida. Apesar das altas taxas cobradas para enterrar os mortos em solos sagrados, ela buscava acolher os pobres mesmo que em lugares menos privilegiados. A resistência católica se voltava aos nãocristãos, em geral os protestantes, na grande maioria imigrantes ou descendentes alemães, que professavam outra crença o luteranismo; isto os levou a construir seus próprios cemitérios para enterrar os mortos.

\footnotetext{
${ }^{3}$ Vale pontuar, conforme Viscardi (2011, p. 180) que "O conceito de pobreza, pelo seu caráter histórico, possui características que variam no tempo e no espaço, como variam as interpretações feitas pelos contemporâneos acerca das razões de sua origem e das diversas alternativas de sua redução". Nessa reflexão compreende-se "pobre" e "pobreza" como mais próximo de desvalido, ou seja, aquela pessoa ou grupo carente de apoio, recurso e suporte socioeconômico, que em grande parte se encontra numa situação de desproteção e desamparo.

${ }^{4}$ A Santa Casa era o local da prática da misericórdia. Instituída por volta de 1498 em Lisboa, teve influência direta na colonização brasileira, com papel específico no amparo dos mais pobres, onde se desempenhava o compromisso das Quatorze Obras de Misericórdia, sendo sete Espirituais (ensinar aos simples, dar bons conselhos, castigar com caridade aos que erram, consolar os tristes, sofrer as injúrias com paciência, perdoar a quem errou, rogar a Deus pelos vivos e pelos mortos) e sete Corporais (curar os enfermos, remir os cativos e visitar os presos, vestir os nus, dar de comer aos famintos, dar de beber aos sedentos, dar pousada aos peregrinos, sepultar os mortos), as quais estavam em sintonia com os ensinamentos de São Tomás de Aquino.
}

Argum., Vitória, v. 9, n. 3, p. 98-112, set./dez. 2017. 
Ao longo do século XIX, o local onde se enterram os mortos passou a sofrer grandes interferências, tanto por parte da Igreja Católica quanto pelas pressões e ideias políticosanitárias, as quais começaram a interferir nos enterros realizados. Os cemitérios passaram a ser um lugar comum para enterrar os mortos e foram construídos afastados do espaço urbano, seguindo algumas orientações: os caixões deveriam ser individuais, os túmulos separados e lacrados e precisaria haver prazo limite para o enterro do morto, evitando-se possíveis contágios, doenças, miasmas, entre outras ocorrências em virtude da presença do corpo morto.

Essas mudanças, gradativamente introduzidas, delegaram como competência de saúde pública municipal o cuidado e o destino ao corpo sem vida. ${ }^{5}$

No final do século XIX a formação das Sociedades de Ajuda Mútua (Socorro Mútuo ou Mutualismo) - enquanto organizações de grupo da própria sociedade - buscava apoiar seus membros face à ausência de um Estado provedor e em razão das precárias condições vividas pelos trabalhadores, sobretudo em consequência da exploração do sistema capitalista. Esse apoio era um alento que socorria as pessoas que dispunham de baixos salários e diante de despesas extras ocorridas em seu cotidiano, como casamentos, aniversários, lazer, nascimento dos filhos, batizados, invalidez, doenças, mortes, entre outras. O cuidado e o trato com a morte eram bastante apreciados pelas agremiações existentes, as quais buscavam dar os devidos méritos aos falecidos e apoiar seus familiares perante os infortúnios do cotidiano.

Embora o Estado fornecesse gratuitamente os serviços funerários aos pobres e indigentes, a maioria das mutuais ocupava-se de fazer o funeral de seus sócios, apoiadas na concepção cultural de o trabalhador ser enterrado preferencialmente com seus recursos e condignamente, demarcando certa distância com o tratamento ofertado pela máquina pública estatal. Nesse sentido, o auxílio-funeral compunha o “[...] leque de 'serviços mínimos' [...]" ofertados pelas mutuais (BATALHA, 1999, p. 6o). No desdobramento de suas ações, era comum as associações também prestarem algum tipo de auxílio às viúvas e aos filhos dos entes falecidos, como meio de guarida e cuidado face ao óbito do arrimo da família.

Dos vários auxílios ofertados pelas mutuais, observa-se que a preocupação com o funeral era bastante difundida e presente nas inúmeras associações existentes, havendo, inclusive, mutuais exclusivamente fundadas para essa finalidade: "A Sociedade de Socorros Urgentes tem por fim especial fazer à sua custa os funerais de seus associados fornecendo às respectivas famílias os indispensáveis confortos morais e materiais em tais casos" (LUCA, 1990, p. 29) também a "Sociedade Beneficente a Última Homenagem" era especializada em

\footnotetext{
${ }^{5} \mathrm{O}$ costume da população de enterrar seus mortos dentro das Igrejas passa a sofrer mudanças com o advento do Iluminismo, o qual influenciou as ideias higienistas e o comportamento da medicina acerca do mal que o cadáver causaria aos vivos. Ao longo do século XIX a teoria dos miasmas, como ficou conhecida, tornou-se uma influência mais presente no país. Com a Proclamação da República e o estabelecimento da separação entre a Igreja e o Estado, os cemitérios passaram a ser de responsabilidade dos municípios, exceto alguns cemitérios que pertenciam às Irmandades, o que ficou assegurado na Primeira Constituição Republicana de 1891: "Os cemitérios terão caráter secular e serão administrados pela autoridade municipal, ficando livre a todos os cultos religiosos a prática dos respectivos ritos em relação aos seus crentes, desde que não ofendam a moral pública e as leis.” Cf. Brasil (1981), Reis (1997) e Rosa (2003).
}

Argum., Vitória, v. 9, n. 3, p. 98-112, set./dez. 2017. 
prestar assistência funerária aos sócios. Além disso, o cuidado e o trato com a morte pareciam evidenciar os méritos a serem atribuídos ao ente falecido: “Algumas entidades despendiam no enterro do sócio quantias proporcionais à graduação do mesmo no quadro social" (LUCA, 1990, p. 29).

$\mathrm{O}$ apoio junto às despesas extras fazia parte do universo das associações. Casamentos, aniversários, nascimento de filhos e batizados eram episódios pouco acessíveis à maioria dos assalariados, se não fossem por intermédio das mutuais, embora prevalecesse a prestação de auxílios de cunho previdenciário: "[...] auxílio a doentes, funeral, tratamento médico, medicamentos, amparo a viúvas, tratamento hospitalar, auxílio a presos, criação de bibliotecas, instrução e auxílios a inválidos [...]" (LUCA, 1990, p. 165). Ou seja, perante um Estado ausente, parte dos cidadãos obtinha alguma forma de atenção por meio de seus próprios recursos.

Havia ainda um grupo seleto de cidadãos amparados pelo Estado a partir da implementação das primeiras legislações no âmbito da política previdenciária ${ }^{6}$. Além dos trabalhadores públicos e militares, algumas categorias profissionais passaram, a partir do início do século $\mathrm{XX}$, a contar com um campo de proteção social público-estatal, apoiados na lógica do seguro social e no vínculo formal de trabalho restrito ao meio urbano. É possível identificar desde então a presença de apoio perante as adversidades do cotidiano, como em decorrência de doenças, acidentes, aposentadoria, morte etc. Foi o que apresentou a tese de Bovolenta (2016), quando identificou formas de atenção ao funeral que ocorriam desde 1926, a partir do Decreto no 5.109, de 20 de dezembro de 1926, que estendia a Lei Eloy Chaves a outras empresas além das voltadas aos trabalhadores ferroviários. Por meio de arranjos distintos e organizações específicas, as legislações no campo previdenciário, que iam sendo implementadas, reconheciam o momento da morte do segurado como objeto de apoio, suporte e proteção.

A unificação, em 1966, das várias Caixas de Aposentadoria e Pensão (CAPs) e dos Institutos de Aposentadoria e Pensão (IAPs) instituiu o Instituto Nacional de Previdência Social (INPS), que passou a ter o auxílio-funeral no rol dos benefícios concedidos aos segurados. Amparado pela Lei Orgânica da Previdência Social (LOPS) Lei no 3.807, de 26 de agosto de 1960, essa atenção garantia aos dependentes do segurado falecido uma importância em dinheiro igual ao dobro do salário-mínimo vigente, e quando não houvesse dependentes era possível indenizar o executor do funeral, desde que as despesas feitas para esse fim fossem devidamente comprovadas.

Com algumas alterações pontuais, essa atenção vigorou desse modo até a década de 1990, quando passou a sofrer os impactos da adoção do ideário neoliberal no país. A partir da implementação da Lei no 8.213, de 24 de julho de 1991, que dispunha sobre "Planos de Benefícios da Previdência Social”, o acesso ao auxílio-funeral passou a se dar por meio do

\footnotetext{
${ }^{6}$ A Lei Eloy Chaves (Decreto Legislativo ${ }^{0}$ 4.682, de 24 de janeiro de 1923), determinava a criação de Caixas de Aposentadoria e Pensão (CAPs) para os empregados das empresas ferroviárias. Baseada na lógica do seguro social, gradativamente outras categorias profissionais foram conquistando suas legislações e criando seus sistemas de proteção social. Vale destacar que a importância das atividades profissionais estava diretamente ligada ao desenvolvimento econômico do país e à sua organização política interna.
} 
corte de renda, destinado aos segurados que recebiam na época até três salários mínimos, perdendo assim seu caráter de universalidade; havia também uma perda efetiva do valor do benefício: de dois para um salário mínimo vigente na época.

O auxílio-funeral da previdência social já era nesse momento compreendido como uma atenção em transição, ou seja, que passaria para a alçada da política de assistência social tão logo houvesse a regulamentação dessa política pública, conforme descrito no corpo da lei: "O pagamento do auxílio-funeral ficará sob a responsabilidade da Previdência Social até que entre em vigor a lei que disponha sobre os benefícios e serviços da Assistência Social” (Art., BRASIL, 1991, não paginado). Além disso, ele, junto ao auxílio-natalidade e à Renda Mensal Vitalícia, não compunha o conjunto de benefícios afiançados no Plano de Benefícios da Previdência Social, mas se encontra nas Disposições Finais e Transitórias da Lei no 8.213/1991. Com a regulamentação da política de assistência social em 1993, essas provisões passaram a compor o rol dos benefícios socioassistenciais: os auxílios-funeral e natalidade, no campo do benefício eventual, e a Renda Mensal Vitalícia, como Benefício de Prestação Continuada7.

De modo específico, apresentam-se a seguir algumas reflexões sobre o auxílio-funeral no âmbito da política de assistência social.

\section{O auxílio-funeral assegurado na Lei Orgânica da Assistência Social (LOAS)}

O auxílio-funeral está afiançado na Lei Orgânica de Assistência Social (LOAS) desde 1993 como uma das provisões compulsórias a serem dispensadas pela assistência social como direito do cidadão e dever do Estado. Trata-se de uma das modalidades de benefício eventual, conforme o Art. 22 dessa legislação.

Elevar essa área ao escopo do direito cria uma relação de dever público-estatal entre Estado e cidadão na materialização do seu campo de atenção, que, a rigor, deve estar distante do caráter assistencialista que acompanhou sua trajetória, embora traços e laços conservadores insistam em compor o cenário dessa política pública, conforme narrou Couto (2015) em Assistência Social: direito ou benesse?.

No compromisso firmado pela assistência social enquanto política pública, reafirma-se o “[...] direito de todos e todas, de usufruírem dos direitos assegurados pelo ordenamento jurídico brasileiro à proteção social não contributiva de assistência social efetiva com dignidade e respeito [...]"conforme o Decálogo dos Direitos Socioassistenciais (BRASIL, 2009b). Assim, a atenção a quem dela necessitar, no acesso aos mínimos sociais ${ }^{8}$ e/ou no enfrentamento a pobreza, deve necessariamente ser conduzida nessa direção, o que orienta as reflexões acerca do objeto desse texto.

\footnotetext{
${ }^{7}$ Em Bovolenta (2016; 2017) é possível ampliar esse campo de análise.

8 "Atualmente a noção de mínimos sociais é muito heterogênea. Varia de acordo com o tipo, a lógica ou o modelo de proteção social adotado (residual ou institucional). Pode ser ampla, concertada e institucionalizada em uns países e restrita, isolada e não institucionalizada em outro. Contudo, os mínimos sociais - uma política mais facilmente verificável nos países capitalistas centrais - são geralmente definidos como recursos mínimos, destinados a pessoas incapazes de prover por meio de seu próprio trabalho a sua subsistência" (PEREIRA, 2002b, p. 16).
} 
De modo específico, compreender o papel que o auxílio-funeral pode assumir permite identificar seu alcance no âmbito da proteção social não contributiva, bem como a direção que o orienta (se no campo do direito ou da ajuda/caridade), reconhecer as incongruências em sua execução e seus limites diante da ocorrência de um óbito na família, ainda mais se considerarmos que tal episódio pode alterar os laços e a dinâmica familiar, especialmente em virtude de seu caráter imprevisível, eventual e inesperado.

No âmbito da assistência social, afiançar o auxílio-funeral se refere a apoiar, cuidar, proteger a família e indivíduos que perdem seus entes queridos. Não se trata de isenções de taxas, pagamento dos ritos fúnebres, concessão do translado ou do enterro e sepultamento do corpo, uma vez que esse apoio se vincula a dar uma destinação ao corpo sem vida, preservando a dignidade e moral da pessoa, compreendendo a morte como parte do ciclo da vida. Portanto, trata-se de procedimentos não reconhecidos como da alçada da política de assistência social. O corpo morto - e todos os procedimentos envolvidos - requer uma atenção específica, um cuidado próprio, um destino correto, os quais se aproximam mais do âmbito da saúde pública, dos cemitérios, serviços funerários (públicos ou privados) e órgãos congêneres, do que da política de assistência social.

Caberia, sim, junto à assistência social, como política de proteção social, apoiar a família que sofre o impacto da morte por meio de um auxílio-funeral, pois, muitas vezes, esse episódio contribui para um desarranjo familiar em virtude de sua ocorrência inesperada. Como uma das modalidades de benefício eventual, é uma atenção provisória, pontual e específica que busca dar apoio ao cidadão que, ao vivenciar este episódio, teria seus laços familiares e afetivos preservados.

Formas de atenção nesses moldes e no âmbito estatal vinculam-se primeiramente junto à classe trabalhadora, seja da iniciativa pública ou privada. É possível identificar formas de atenção nas incipientes legislações que passam a regular um campo de proteção social destinado ao trabalhador com vínculo formal de trabalho, como brevemente descrito.

Segundo o Relatório sobre o Levantamento Nacional de Benefícios Eventuais de 2009 (BRASIL, 2009a), o auxílio-funeral é a modalidade de benefício eventual mais presente nos municípios, o que pode indicar que a assistência social vem se comportando como pagadora das taxas que envolvem o óbito e/ou como facilitadora da burocracia acerca do funeral.

No mapeamento de 2009 foi possível identificar as formas de oferta do auxílio-funeral existentes, conforme dados da Tabela 1.

Tabela 1.

Formas de oferta do auxílio-funeral mapeadas pelo Relatório Nacional de 2009

\begin{tabular}{|c|c|c|}
\hline Formas de oferta & \multicolumn{2}{|c|}{ Auxílio-Funeral } \\
\hline & № & $\%$ \\
\hline $\begin{array}{l}\text { Na forma de transferência monetária, distribuição de bens e } \\
\text { ressarcimento }\end{array}$ & 725 & 18,6 \\
\hline Somente na forma de distribuição de bens & 2160 & 55,3 \\
\hline Somente na forma de ressarcimento & 289 & 7,4 \\
\hline Somente na forma de transferência monetária & 730 & 18,7 \\
\hline Total de Municípios & 3904 & 100 \\
\hline
\end{tabular}

Argum., Vitória, v. 9, n. 3, p. 98-112, set./dez. 2017. 
Interessante observar que a maior forma da oferta, 55,3\%, se concentra na distribuição de bens, o que nos permite identificar uma suposta resistência da política em transferir recursos financeiros diretamente ao cidadão. Possivelmente essa resistência quanto à provisão em auxílio financeiro se explique pelo legado da assistência social em atender pessoas consideradas incultas na administração de recursos financeiros. Ou seja, "o pobre" (e não o cidadão) pode não saber usar adequadamente a transferência monetária que recebeu ou "cair em tentação" e utilizar esses recursos para outras finalidades. Esta leitura ajuda a explicar a predileção do Estado em priorizar a distribuição de bens materiais ante a transferência monetária. Todavia, defende-se aqui que não é uma competência estatal fiscalizar ou controlar o modo como o benefício repassado ao cidadão será utilizado. Esse comportamento, sua reiteração e defesa, evidencia um Estado Tutelador que não reconhece a autonomia do indivíduo, tratando-o como incapaz de administrar seus recursos financeiros e de estabelecer suas prioridades e necessidades. No Censo SUAS também é possível identificar a presença dessa atenção na maioria dos municípios brasileiros.

Tabela 2

Concessão do auxílio-funeral pelos municípios a partir dos Censos SUAS 2011 a 2014

\begin{tabular}{|c|c|c|c|c|c|c|c|c|}
\hline & \multicolumn{3}{|c|}{2011} & \multirow{2}{*}{$\frac{2012}{\%}$} & \multicolumn{2}{|c|}{2013} & \multicolumn{2}{|c|}{2014} \\
\hline & № & $\%$ & № & & № & $\%$ & № & $\%$ \\
\hline SIM & $\begin{array}{c}4 \\
862\end{array}$ & 90 & 4675 & 88 & 5249 & 96 & $\begin{array}{c}5 \\
289\end{array}$ & 95 \\
\hline NÃO & 229 & 4 & 330 & 6 & 193 & 4 & 231 & 4 \\
\hline $\mathbf{N R}^{\mathbf{1}}$ & 325 & 6 & 310 & 6 & o & 0 & 50 & 1 \\
\hline Base & 5416 & 100 & 5315 & 100 & 5442 & 100 & 5570 & 100 \\
\hline
\end{tabular}

Os números mapeados mostram uma importante presença dessa atenção no conjunto dos municípios brasileiros, o que não quer dizer ela esteja regulamentada e que conte com orçamento próprio e permanente. Ou seja, em 95\% dos municípios, conforme o Censo SUAS 2014, existe a concessão do auxílio-funeral por parte da política de assistência social. Indagamo-nos sobre a quem se destina esta atenção e o modo como ela se comporta na prática.

Também é possível identificar que o auxílio-funeral é a segunda atenção mais concedida junto aos CRAS, conforme os dados da Tabela 3.

Tabela 3

Modalidades de BE concedidas no CRAS

\begin{tabular}{|c|c|c|c|c|c|c|c|c|c|c|c|}
\hline \multirow[b]{2}{*}{ BE } & & \multicolumn{2}{|c|}{2010} & \multicolumn{2}{|c|}{2011} & \multicolumn{2}{|c|}{2012} & \multicolumn{2}{|c|}{2013} & \multicolumn{2}{|c|}{2014} \\
\hline & & № & $\%$ & № & $\%$ & № & $\%$ & № & $\%$ & № & $\%$ \\
\hline \multirow{2}{*}{$\begin{array}{l}\text { Auxílio- } \\
\text { Funeral }\end{array}$} & $\mathbf{S}$ & 2100 & 31 & 2555 & 34 & 2801 & 39 & 3150 & 40 & 3589 & 44 \\
\hline & $\mathbf{N}$ & 1344 & 20 & 1744 & 24 & 1868 & 6 & 1820 & 23 & 1917 & 24 \\
\hline \multirow{2}{*}{$\begin{array}{c}\text { Auxílio- } \\
\text { Natalidade }\end{array}$} & $\mathbf{S}$ & 1525 & 22 & 1937 & 26 & 2189 & 31 & 2538 & 32 & 2978 & 37 \\
\hline & $\mathbf{N}$ & 1919 & 29 & 2362 & 32 & 2480 & 34 & 2432 & 31 & 2528 & 31 \\
\hline \multirow{2}{*}{$\begin{array}{c}\text { Auxílio } \\
\text { alimentar } \\
\text { (cesta básica) }\end{array}$} & $S$ & 3054 & 45 & 3837 & 52 & 4144 & 58 & 4398 & 56 & 5015 & 62 \\
\hline & $\mathrm{N}$ & 390 & 6 & 462 & 6 & 525 & 7 & 572 & 7 & 491 & 6 \\
\hline
\end{tabular}

Argum., Vitória, v. 9, n. 3, p. 98-112, set./dez. 2017. 


\begin{tabular}{c|c|c|c|c|c|c|c|c|c|c|c}
\hline & S & 1291 & 19 & 2179 & 29 & 2201 & 31 & 2275 & 29 & 2572 & 32 \\
Passagens & N & 2153 & 32 & 2120 & 29 & 2468 & 34 & 2695 & 34 & 2934 & 36 \\
\hline & S & 1291 & 20 & 1543 & 21 & 1701 & 24 & 1709 & 22 & 1921 & 24 \\
Outros & $\mathbf{N}$ & 2153 & 31 & 2756 & 37 & 2968 & 41 & 3261 & 41 & 3585 & 44 \\
\hline N R & & 3357 & 49 & 3176 & 42 & 2556 & 35 & 2913 & 37 & 2582 & 32 \\
Base & $\mathbf{6 8 0 1}$ & $\mathbf{1 0 0}$ & $\mathbf{7 4 7 5}$ & $\mathbf{1 0 0}$ & $\mathbf{7 2 2 5}$ & $\mathbf{1 0 0}$ & $\mathbf{7 8 8 3}$ & $\mathbf{1 0 0}$ & $\mathbf{8 0 8 8}$ & $\mathbf{1 0 0}$ \\
\hline
\end{tabular}

Fonte: Censo SUAS 2010, 2011, 2012, 2013 e 2014.

i: Não Respondeu. O número de municípios que não respondeu foi o mesmo em cada um dos benefícios referidos dentro do mesmo ano.

Legenda: S: Sim; N: Não

Esses números apresentados mostram a presença do auxílio-funeral junto à política de assistência social. Questiona-se pensar sobre qual prisma essa provisão vem sendo concedida, a quem se destina e como ele é de fato gerido e executado. Se há consonância entre os preceitos legais e seu reconhecimento real, e, por fim, se há cooperação na regulamentação, gestão e financiamento entre municípios e estados federados, além do Distrito Federal, entes responsáveis por essa provisão.

O olhar mais próximo sobre a cidade de São Paulo nos permite refletir sobre algumas dessas questões postas.

\section{O auxílio-funeral na cidade de São Paulo e os percalços ao direito de morrer}

A atenção ao funeral na cidade de São Paulo é atualmente uma incumbência da Secretaria Municipal de Serviços, uma autarquia que cuida da limpeza da cidade, da coleta de lixo e da gestão de cemitérios. Ao percorrer a história da cidade, depara-se com os registros de que os sepultamentos realizados tinham estreita relação com a classe social do cidadão, como brevemente narrado. Os mais ricos (pessoas da elite e do clero) eram enterrados dentro das igrejas católicas. Aos mais pobres (mesmo os membros da classe média), a última morada encontrava-se em espaços descobertos, lugares de fronteiras ou ao lado das igrejas. Outros templos possuíam seus pequenos cemitérios contíguos.

Na cidade de São Paulo, os condenados pela justiça que morriam na forca não podiam ser enterrados em solo sagrado; diante disso, a saída encontrada pela Igreja foi construir um cemitério distante da cidade, que recebeu o nome de "Cemitério dos Aflitos"9, tendo seu primeiro sepultamento ocorrido em 3 de outubro de 1775, quando foi inaugurado. Neste espaço a céu aberto eram enterrados os indigentes, os escravos (que não pertenciam à Irmandade do Rosário) e os condenados à morte.

\footnotetext{
${ }^{9}$ Este cemitério se localizava onde hoje é o bairro da Liberdade em São Paulo. Com a inauguração do Cemitério da Consolação (primeiro cemitério público municipal), em 1958, foram proibidos os sepultamentos tanto dentro das igrejas quanto neste local, que, por ficar abandonado, encontrou-se em ruínas em 1885. Em vez de restaurá-lo, o então bispo da época - D. Lino Deodato Rodrigues de Carvalho buscou povoar o entorno do cemitério, com a venda de terrenos e retirada dos restos mortais do lugar. Hoje só permanece neste local, como memória, a igreja dos aflitos, que fora construída em 1779, local onde os mortos recebiam a última oração antes de serem sepultados.
} 
Atualmente na cidade de São Paulo os indigentes, desconhecidos e falecidos não reclamados são assim qualificados pelo Serviço de Verificação de Óbitos (SVO), órgão vinculado à Universidade de São Paulo (USP), que cuida dos cadáveres com morte natural e sem identificação; as mortes violentas e suspeitas são referenciadas junto ao Instituto Médico Legal (IML). Os familiares têm 72h para reclamar o corpo junto a esses órgãos; após esse período, segundo norma estadual de 1993, o corpo pode ser enterrado. O Serviço Funerário do Município de São Paulo (SFMSP) efetua os sepultamentos dos indigentes em valas comuns em três cemitérios da cidade, são eles: Dom Bosco, Vila Formosa I e Vila Formosa II.

Ocorre que, por não haver o cruzamento de informações entre o Banco de Dados do SVO e o de pessoas desaparecidas reclamadas em Boletim de Ocorrência (BO), muitas pessoas identificadas (cadastradas publicamente, com número de Registro Geral (RG)) são enterradas como indigentes de fato o ser. Em reportagem junto a Folha de São Paulo (TUROLLO; PAGNAN, 2014), a Promotoria relatou que processará o estado de São Paulo por enterrar pessoas identificadas em valas comuns. Foram mais de 3.000 enterrados sem aviso às famílias nos últimos 15 anos.

Ainda não houve, portanto, como ainda não há na cidade de São Paulo, o reconhecimento dos auxílios compulsórios: natalidade e funeral, previstos na LOAS desde 1993 junto à política de assistência social, contrariando, inclusive, o que consta na Lei Orgânica do Município de São Paulo, ao observar essas formas de atenção como incumbência do ente municipal e da alçada dessa política pública. No campo referente à assistência social, é dever do município:

III - regulamentar e prover recursos para manter o sistema não contributivo de transferência de renda através de benefícios a quem dele necessitar, tais como:

[...] benefícios em caráter eventual para situações de emergência como: decorrentes de calamidades públicas, morte familiar (auxílio-funeral) e necessidades circunstanciais consideradas de risco pessoal e social;

a) auxílio-natalidade para famílias mono e multinucleares em situação de risco; [...].

(SÃO PAULO, 1990, p. 69)

Na cidade de São Paulo o serviço funerário de cunho municipal ${ }^{10}$ - trata-se de uma autarquia que cuida dos procedimentos referentes ao óbito, administra e fiscaliza os cemitérios, presta serviços auxiliares e administrativos junto ao Cartório de Registro Civil. O translado do corpo (inclusive para outros municípios e estados) também é uma das atribuições desse serviço, realizado pelo carro do serviço funerário, também conhecido como rabecão em algumas regiões do país.

Mesmo sendo um serviço público e municipal, há um custo a ser pago pelos familiares ou responsáveis pelo morto; o valor cobre as despesas, taxas e impostos do funeral (que envolvem o velório, o translado do corpo, o fornecimento de urnas ou caixões mortuários etc.), além dos serviços extras (ou necessários) como contratação de homenagem, cremação, locação de terrenos, ossários, exumações e serviços administrativos.

\footnotetext{
${ }^{10}$ Por meio da Lei $\mathrm{n}^{\circ}$ 69, de 2 de abril de 1876, firmou-se contrato entre a Santa Casa de Misericórdia e a Assembleia Provincial, criando-se o Serviço Funerário Municipal. Somente em 1958 é que esse órgão tornouse uma autarquia, assegurada pela Lei $n^{0} 5 \cdot 562$.
}

Argum., Vitória, v. 9, n. 3, p. 98-112, set./dez. 2017. 
Para os cidadãos que não podem arcar com o ônus do funeral, o Serviço Funerário do Município de São Paulo dispõe de funerais gratuitos. Por meio da Lei no ${ }^{11.083 / 91 ~ s a ̃ o ~}$ concedidos a gratuidade do sepultamento, dos meios e procedimentos a ele necessários, não sendo exigido apresentar atestado de pobreza, bastando apenas declarar esta condição11. No entanto, recorrer ao direito da gratuidade do sepultamento na cidade de São Paulo parece gerar certo constrangimento à família e/ou amigos do indivíduo morto, ou ainda ser algo que se utiliza "em último caso", isso em virtude da oferta de bens e serviços ser inferior àquela fornecida quando se paga pelo sepultamento. No caso da gratuidade, o caixão é simples, não há flores nem velório, e a permanência do corpo para despedida é de 15-30 minutos.

Essa realidade foi captada pelo trabalho de Ladeira, ao identificar a violação de direitos vivenciada pelas famílias em luto, sobretudo as marcadas pela situação de pobreza.

As cerimônias de gratuidade contam com infraestrutura precária para acolhimento. Na capela não há bebedouro [...]; os banheiros não possuem papel higiênico, sabonete, nem toalha [...], além de terem condições de higiene precárias (LADEIRA, 2010, p. 88).

Essa narrativa reforça a compreensão de que a atenção voltada ao pobre (e não ao cidadão) é sempre de baixa qualidade e inferior a quando se paga pelo serviço, o que permite compreender a resistência de muitas famílias em recorrer à gratuidade do funeral, uma vez que esse não preserva a dignidade do morto e nem da família enlutada. Assim, em razão da má qualidade dos serviços prestados, frieza e insensibilidade dos agentes funerários ante a esse momento de dor e sofrimento, as famílias fazem tudo o que é possível para angariar os recursos necessários que permitam um sepultamento minimamente respeitável, como uma forma de preservar a honra e a memória do morto.

Essa situação demonstra como as relações de mercado se sobressaem às necessidades humanas e sociais. Ou seja, tem o melhor serviço quem paga por ele; o que faz com que as diferenças sociais e econômicas exploradas pelo sistema capitalista não cessem nem mesmo no momento da morte. Isso se agrava ao reconhecer a omissão e negligência do Estado que se rende às normas e regras do mercado, oferecendo às famílias uma atenção inferior ao que se adquire pela relação de consumo. Essas identificações evidenciam os desafios de se construir - e efetivar - um sistema de proteção social que reconheça o direito na perspectiva de cidadania e não de consumidor.

Não há, portanto, na cidade de São Paulo, a implementação do auxílio-funeral no campo da proteção social não contributiva, compreendido como um apoio, suporte, auxílio à família perante a vivência do óbito de um de seus membros. $\mathrm{O}$ mais próximo, como vimos, é o reconhecimento de um apoio, ainda que limitado e reducionista, para enterrar o morto, caso a família não tenha condições financeiras de arcar com os gastos do funeral.

\footnotetext{
${ }^{11}$ Além dessa legislação, também poderá usufruir da dispensa de pagamento de taxas, emolumentos e tarifas a família de pessoa que tiver doado algum órgão para fins de transplante médico. Para tanto, na contratação do funeral, a família deverá apresentar o comprovante de doação de órgãos do falecido, bem como da imediata comunicação do óbito à instituição médica habilitada a realizar o transplante, conforme Lei $\mathrm{n}^{\mathrm{o}}$ 11.479/94, regulamentada pelo Decreto no $35 \cdot 198 / 95$ (SÃO PAULO, 1995).
}

Argum., Vitória, v. 9, n. 3, p. 98-112, set./dez. 2017. 


\section{Considerações finais}

Essa reflexão buscou trazer algumas considerações acerca do auxílio-funeral afiançado na política de assistência social. Sem esgotar o debate, trata-se de uma atenção no campo da proteção social não contributiva que busca apoiar, auxiliar, amparar a família diante a vivência do óbito de um de seus membros, sobretudo considerando este episódio como atípico, eventual, inesperado, parte do ciclo da vida e presente no cotidiano de qualquer cidadão.

A breve narrativa sobre o papel do sepultamento, a partir de todo seu rito, burocracia e história, buscou mostrar que o enterro do corpo morto não é dever da política de assistência social. Em outros termos, não cabe a esta área ser a facilitadora da burocracia que envolve o funeral ou ainda a pagadora de taxas de cemitérios e enterros, cujas famílias não possam arcar com esse ônus. Enterrar o corpo morto é uma questão de saúde pública e um dever público-estatal, que não cabe à política de assistência social gerir e executar. Caberia, sim, a esta área o papel de garantir apoio, suporte, amparo e proteção à família que vivencia o óbito de um de seus membros.

Como uma das modalidades de benefício eventual, é papel dos municípios, estados federal e Distrito Federal a regulamentação, gestão e financiamento desse campo de atenção. Assim, ficaria a cargo do município, em cooperação com o ente estadual, definir como o auxíliofuneral se materializaria, bem como assegurar orçamento e o modo como seria gerido e executado ${ }^{12}$.

No entanto, ao aproximar-se da realidade da cidade de São Paulo, é possível identificar a omissão e negligência por parte do Estado em não afiançá-lo junto à política de assistência social, como preveem a LOAS e outras legislações subsequentes. Além disso, como modalidade de benefício eventual, o município não conta com apoio técnico e financeiro por parte da esfera estadual no que tange à gestão, regulamentação e financiamento desse benefício. De acordo com o último Censo SUAS analisado, de 2014, o estado de São Paulo não tem o benefício eventual regulamentado e não auxilia ou coopera com nenhum dos seus 645 municípios $^{13}$.

Longe de esgotar o debate, defende-se que essas considerações componham arenas de debates, que sejam publicizadas e propulsoras de mudanças. Que essas mudanças levem ao reconhecimento do auxílio-funeral no campo dos direitos socioassistenciais, que permitam assegurar apoio e suporte à família perante a vivência do óbito, que definam as especificidades e atribuições de cada área, de modo que a política de assistência social cumpra seu papel no campo da proteção social e não como intermediadora das omissões e

\footnotetext{
${ }^{12} \mathrm{Na}$ cidade de São Paulo, o benefício eventual está regulamentado desde 2009, por meio da Portaria $\mathrm{n}^{\mathrm{o}} 44$. No entanto, o auxílio-funeral não compõe as ofertas dispensadas. Do mesmo modo, o município não conta com apoio financeiro por parte do estado paulista.

${ }^{13}$ Em Bovolenta (2016 e 2017) é possível identificar o cenário da gestão, regulamentação e financiamento do benefício eventual em âmbito estadual. De acordo com o último Censo SUAS analisado, 2014, doze estados relataram possuir regulamentação para benefício eventual: AP, CE, PI, BA, MA, MG, RJ, PR, SC, MS, MT, GO, além do DF.
}

Argum., Vitória, v. 9, n. 3, p. 98-112, set./dez. 2017. 
negligências de outras áreas, ou ainda como intercessora dos pobres no acesso a suas necessidades básicas.

\section{Referências}

BOVOLENTA. G. A. Benefício Eventual e Assistência Social: uma emergência: uma proteção social?. Jundiaí: Paco, 2017.

BOVOLENTA. G. A. O benefício eventual da LOAS como garantia de proteção social. Tese (Doutorado em Serviço Social)-Pontifícia Universidade Católica de São Paulo, São Paulo, 2016.

CAMARGO, L. S. Viver e Morrer em São Paulo: a vida, as doenças e a morte na cidade do século XIX. 2007. Tese (Doutorado em História Social)-Pontifícia Universidade Católica de São Paulo, São Paulo, 2007.

COUTO, B. R. Assistência social: direito ou benesse?. Serviço Social e Sociedade, São Paulo, n. 124, p. 665-677, out./dez. 2015.

BATALHA, C. H. M. Sociedades de trabalhadores no Rio de Janeiro do século XIX: algumas reflexões em torno da formação da classe operária. Cad. AEL, Campinas, v. 6, n. 10-11, 1999.

BRASIL. Ministério do Desenvolvimento Social e Combate à Fome. Norma Operacional Básica: NOB/SUAS. Brasília (DF), 2012.

BRASIL. Presidência da República. Lei no 12.435, de 6 de Julho de 2011. Diário Oficial da União, Brasília (DF), 7 jul. 2011. Disponível em:

<http://www.planalto.gov.br/ccivil_03/_Ato2011-2014/2011/Lei/L12435.htm>. Acesso em: 30 jul. 2015 .

BRASIL. Ministério do Desenvolvimento Social e Combate à Fome. Relatório sobre o Levantamento Nacional de Benefícios Eventuais. Brasília (DF), 2009a. Disponível em: <http://www.cogemas.pr.gov.br/arquivos/File/Documento/Relatorio_BE_Final.pdf>. Acesso em: 30 maio 2015.

BRASIL. Ministério do Desenvolvimento Social e Combate à Fome. Conselho Nacional de Assistência Social. Decálogo dos Direitos Socioassistenciais. Brasília (DF), 20ogb.

Disponível em < https://fpabramo.org.br/acervosocial/wpcontent/uploads/sites/7/2017/o8/o44.pdf>. Acesso em 19 dez. 2016.

BRASIL. Presidência da República. Decreto no 6.307, de 14 de dezembro de 2007. Diário Oficial da União, Brasília (DF), 17 dez. 2007. Seção 1, p. 8. Disponível em:

<http://www2.camara.leg.br/legin/fed/decret/2007/decreto-6307-14-dezembro-2007566562-publicacaooriginal-90106-pe.html>. Acesso em: 30 ago. 2015.

BRASIL. Ministério do Desenvolvimento Social e Combate à Fome. Conselho Nacional de Assistência Social. Resolução no 212, de 19 de outubro de 2006. Diário Oficial da União, 
Brasília (DF), 27 out. 2006. Seção 1. Disponível em:

<http://www.mds.gov.br/cnas/legislacao/resolucoes/arquivos-2006/CNAS\%202006\%20\%20212\%20-\%2019.10.2006.doc/view>. Acesso em: 20 mar. 2015.

BRASIL. Ministério do Desenvolvimento Social e Combate à Fome. Norma Operacional Básic: NOB/SUAS. Brasília (DF), 2005.

BRASIL. Ministério do Desenvolvimento Social e Combate à Fome. Política Nacional de Assistência Social. Brasília (DF), 2004.

BRASIL. Lei no 8.213, de 24 de julho de 1991. Diário Oficial da União, Brasília (DF), 25 jul. 1991. Disponível em: <http://www.planalto.gov.br/ccivil_03/leis/L8213cons.htm>. Acesso em: 21 maio 2015.

BRASIL. Constituição (1891). Constituição da República dos Estados Unidos do Brasil (de 24 de Fevereiro de 1891). Diário Oficial da União, Rio de Janeiro, 24 fev. 1981.

BRASIL. Lei no 3.807, de 26 de agosto de 1960. Diário Oficial da União, Brasília (DF), 5 set. 1960. Disponível em: <http://www.planalto.gov.br/ccivil_o3/leis/1950-1969/L3807.htm>. Acesso em: 16 maio 2015 .

BRASIL. Ministério do Desenvolvimento Social e Combate à Fome. Conselho Nacional de Assistência Social. Resolução no 39, de 9 de Dezembro de 2010. Diário Oficial da União, Brasília (DF), 16 dez. 2010. Disponível em:

<http://conselho.saude.gov.br/ultimas_noticias/2011/relatorio/resolucao_cnas_39.pdf>. Acesso em: 20 abr. 2015.

FRAGA, W. Uma esmola “pelo amor de Deus”. A História da Pobreza. História Viva, São Paulo, ano 11, n. 131, set. 2014.

FRANCO, R. Todos pobres, mas nem todos iguais. A História da Pobreza. História Viva, São Paulo, ano 11, n. 131, set. 2014.

LADEIRA, T. C. A decadência do espaço social e subjetivo da dor: um estudo sobre o luto de morte com famílias do Lajeado: São Paulo (SP). 2010. Dissertação (Mestrado em Serviço Social)-Pontifícia Universidade Católica de São Paulo, São Paulo, 2010.

LUCA, T. R. O sonho do futuro assegurado. São Paulo: Contexto; Brasília (DF): CNPq, 1990.

MALLOY, J. Política de Previdência Social no Brasil. Rio de Janeiro: Graal, 1986.

PAGOTO, A. A. Do âmbito sagrado da Igreja ao Cemitério Público - Transformações Fúnebres em São Paulo 1850/186o. Dissertação (Mestrado em História Social) - Pontifícia Universidade Católica de São Paulo (PUC-SP), São Paulo, 2002. 
PEREIRA, P. A. P.; Nasser, I. R.; Campos, S. M. A.; Os percalços dos Benefícios Eventuais regidos pela LOAS. Cadernos do Ceam: Núcleo de Estudos e Pesquisa em Política Social da UnB, Brasília (DF), ano 3, n. 11, p. 113-135, 2002.

PEREIRA, P. A. P. Necessidades humanas: subsídios à crítica dos mínimos sociais. 2. ed. São Paulo: Cortez, 2002b.

PEREIRA, P. A. P. Panorama do processo de regulamentação e operacionalização dos benefícios eventuais regidos pelas LOAS. Brasília (DF): Secretaria de Avaliação e Gestão da Informação do Ministério do Desenvolvimento Social e Combate à Fome, 2010. (Cadernos de Estudos Desenvolvimento Social em Debate, n. 12).

REIS, J. J. O cotidiano da morte no Brasil Oitocentista. In: ALENCASTRO, Luiz Felipe (Org.). História da vida privada no Brasil: Império. v. 2. São Paulo: Companhia das Letras, 1997.

ROSA, E. T. A relação das áreas de cemitérios públicos com o crescimento urbano. 2003. Dissertação (Mestrado em Geografia)-Universidade Federal de Santa Catarina, Florianópolis, 2003.

SÃO PAUlO (Município). Lei Orgânica do Município de São Paulo. São Paulo, 1990. Disponível em:

<http://www.prefeitura.sp.gov.br/cidade/secretarias/upload/educacao/cme/LOM.pdf>. Acesso em: 30 ago. 2015.

SÃO PAULO (Município). Decreto no. 35.198, de 14 de julho de 1995. São Paulo, 1995. Disponível em: <http://cmspbdoc.inf.br/iah/fulltext/decretos/D35198.pdf>. Acesso em: 20 mar. 2015.

SPOSATI, A. Vida urbana e gestão da pobreza. São Paulo: Cortez, 1988.

TUROLLO JR, Reynaldo; PAGNAN, Rogério. Ministério Público de São Paulo vai pedir exumação de 'indigentes com RG'. Folha de S. Paulo, São Paulo, 23 abr. 2014. Cotidiano. Disponível em: <http://www1.folha.uol.com.br/fsp/cotidiano/162578-ministerio-publico-desp-vai-pedir-exumacao-de-indigentes-com-rg.shtml>. Acesso em: 23 abr. 2014.

VELLASCO, I. A. Clientelismo, ordem privada e Estado no Brasil oitocentista: notas para um debate. In: CARVALHO, José Murilo de; NEVES, Lúcia Maria Bastos Pereira (Orgs.). Repensando o Brasil do Oitocentos: cidadania, política e liberdade. Rio de Janeiro: Civilização Brasileira, 2009. p. 71-99.

VISCARDI, C. M. R. Pobreza e assistência no Rio de Janeiro na Primeira República. Hist. cienc. Saúde-Manguinhos, Rio de Janeiro , v. 18, supl. 1, p. 179-197, dec. 2011 . Disponível em:<http://www.scielo.br/scielo.php?script=sci_arttext\&pid=So10459702011000500010\&lng= en\&nrm=iso >. Acesso em: 27 nov. 2017.

Gisele Aparecida BOVOLENTAAssistente Social. Mestre e Doutora em Serviço Social pela PUCSP. 